University of Nebraska - Lincoln

DigitalCommons@University of Nebraska - Lincoln

\title{
The Role of Shewanella oneidensis MR-1 Outer Surface Structures in Extracellular Electron Transfer
}

\author{
Rachida A. Bouhenni \\ Summa-Health System \\ Gary J. Vora \\ Naval Research Laboratory \\ Justin C. Biffinger \\ US Naval Research Laboratory, justin.biffinger@nrl.navy.mil \\ Sheetal Shirodkar \\ University of Wisconsin-Milwaukee \\ Ken Brockman \\ University of Wisconsin-Milwaukee \\ See next page for additional authors
}

Follow this and additional works at: https://digitalcommons.unl.edu/usnavyresearch

Part of the Operations Research, Systems Engineering and Industrial Engineering Commons

Bouhenni, Rachida A.; Vora, Gary J.; Biffinger, Justin C.; Shirodkar, Sheetal; Brockman, Ken; Ray, Ricky; Wu, Peter; Johnson, Brandy J.; Biddle, Eulandria M.; Marshall, Matthew J.; Fitzgerald, Lisa A.; Little, Brenda J.; Fredrickson, Jim K.; Beliaev, Alexander S.; Ringeisen, Bradley R.; and Saffarini, Daad A., "The Role of Shewanella oneidensis MR-1 Outer Surface Structures in Extracellular Electron Transfer" (2010). U.S. Navy Research. 16.

https://digitalcommons.unl.edu/usnavyresearch/16

This Article is brought to you for free and open access by the U.S. Department of Defense at DigitalCommons@University of Nebraska - Lincoln. It has been accepted for inclusion in U.S. Navy Research by an authorized administrator of DigitalCommons@University of Nebraska - Lincoln. 


\section{Authors}

Rachida A. Bouhenni, Gary J. Vora, Justin C. Biffinger, Sheetal Shirodkar, Ken Brockman, Ricky Ray, Peter Wu, Brandy J. Johnson, Eulandria M. Biddle, Matthew J. Marshall, Lisa A. Fitzgerald, Brenda J. Little, Jim K. Fredrickson, Alexander S. Beliaev, Bradley R. Ringeisen, and Daad A. Saffarini 


\title{
The Role of Shewanella oneidensis MR-1 Outer Surface Structures in Extracellular Electron Transfer
}

\author{
Rachida A. Bouhenni ${ }^{\mathrm{a}, \mathrm{f}}$ Gary J. Vora, ${ }^{\mathrm{b}}$ Justin C. Biffinger, ${ }^{\mathrm{c}}$ Sheetal Shirodkar,${ }^{\mathrm{a}}$ Ken Brockman, ${ }^{\mathrm{a}}$ Ricky Ray, ${ }^{\mathrm{d}}$ \\ Peter Wu, ${ }^{\mathrm{c}}$ Brandy J. Johnson, ${ }^{\mathrm{b}}$ Eulandria M. Biddle, ${ }^{\mathrm{a}}$ Matthew J. Marshall, ${ }^{\mathrm{e}}$ Lisa A. Fitzgerald, ${ }^{\mathrm{c}}$ Brenda J. Little, ${ }^{\mathrm{d}}$ \\ Jim K. Fredrickson, ${ }^{\mathrm{e}}$ Alexander S. Beliaev, ${ }^{\mathrm{e}}$ Bradley R. Ringeisen, ${ }^{\mathrm{c} *}$ Daad A. Saffarini ${ }^{\mathrm{a} *}$ \\ a Department of Biological Sciences, University of Wisconsin-Milwaukee, WI 53211, USA \\ b Center for Bio/Molecular Science \& Engineering, Naval Research Laboratory, Washington, DC, 20375, USA \\ c Chemistry Division, Naval Research Laboratory, Washington, DC, 20375, USA \\ d Oceanography Division, Naval Research Laboratory, John C. Stennis Space Center, MS, 39529, USA \\ e Pacific Northwest National Laboratory, Richland, WA 99354, USA \\ f Summa-Health System, 525 East Market St, Akron, OH 44304, USA \\ *e-mail: daads@uwm.edu; bradley.ringeisen@nrl.navy.mil
}

Received: June 15, 2008

Accepted: October 1, 2009

\begin{abstract}
The ability of the metal reducer Shewanella oneidensis MR-1 to generate electricity in microbial fuel cells (MFCs) depends on the activity of a predicted type IV prepilin peptidase; PilD. Analysis of an S. oneidensis MR-1 pilD mutant indicated that it was deficient in pili production (Msh and type IV) and type II secretion (T2S). The requirement for $\mathrm{T} 2 \mathrm{~S}$ in metal reduction has been previously identified, but the role of pili remains largely unexplored. To define the role of type IV or Msh pili in electron transfer, mutants that lack one or both pilus biogenesis systems were generated and analyzed; a mutant that lacked flagella was also constructed and tested. All mutants were able to reduce insoluble $\mathrm{Fe}$ (III) and to generate current in MFCs, in contrast to the T2S mutant that is deficient in both processes. Our results show that loss of metal reduction in a PilD mutant is due to a T2S deficiency, and therefore the absence of $c$ cytochromes from the outer surface of MR-1 cells, and not the loss of pili or flagella. Furthermore, MR-1 mutants deficient in type IV pili or flagella generated more current than the wild type, even though extracellular riboflavin levels were similar in all strains. This enhanced current generating ability is in contrast to a mutant that lacks the outer membrane $c$ cytochromes, MtrC and OmcA. This mutant generated significantly less current than the wild type in an MFC and was unable to reduce Fe(III). These results indicated that although nanofilaments and soluble mediators may play a role in electron transfer, surface exposure of outer membrane $c$ cytochromes was the determining factor in extracellular electron transfer in S. oneidensis MR-1.
\end{abstract}

Keywords: Shewanella oneidensis MR-1, Current production, Electron transfer, Nanofilaments, Riboflavin, Fuel cells

DOI: 10.1002/elan.200880006

\section{Introduction}

Shewanella oneidensis MR-1 is a facultative anaerobe that uses more than 14 terminal electron acceptors for respiration. These include $\mathrm{O}_{2}$, fumarate, as well as soluble and solid forms of metals including chromium, iron, manganese, technetium and uranium [1-7]. Anaerobic reduction of poorly soluble electron acceptors such as $\mathrm{Fe}(\mathrm{III})$ and Mn(IV) oxides occurs extracellularly through multi-heme $c$ cytochromes located on the outer membrane. In $S$. oneidensis MR-1, metal reduction involves a periplasmic decaheme $c$ cytochrome (MtrA), a porin-like outer membrane protein $(\mathrm{MtrB})$, and two decaheme $c$ cytochromes (MtrC and OmcA; 8-11]. MtrC and OmcA are exposed on the cell surface [10] and are thought to participate directly in electron transfer to the metal oxides [12, 13]. Outer membrane $c$ cytochromes have been identified in other dissimilatory metal reducing bacteria such as Shewanella putrefaciens sp200, Geobacter metallireducens, and $G$. sulfurreducens [14-17]. In several of these bacteria, targeting of $c$ cytochromes and proteins involved in metal reduction to the outer membrane is accomplished by the type II secretion system (T2SS). In S. oneidensis MR-1 and $S$. putrefaciens sp200, deficiencies in T2SS lead to loss of metal reduction and lack of surface exposure of $c$ cytochromes [14, 18]. Similarly, the G. sulfurreducens multicopper outer membrane protein OmpB is accomplished by the T2SS [19].

Pilus-like structures, or nanowires, and soluble electron shuttles such as riboflavins, have also been proposed to play roles in metal reduction and current production in microbial fuel cells (MFCs). Preliminary experiments have shown nanofilaments of Shewanella and Geobacter species to be conductive [20,21], although the mechanism and extent of their conductivity have not been determined. These nanofilaments have also been hypothesized to serve as direct electron conduits between the cell and solid electron acceptors [20, 21]. In addition to nanofilaments and outer membrane $c$ cytochromes, redox active mediator molecules, 
such as riboflavins, are thought to transfer electrons to insoluble electron acceptors and to electrodes in MFCs [22-24].

Recently, a mutant with a transposon insertion in pilD (locus tag SO_0414), which is predicted to encode a type IV prepilin peptidase, was reported to be deficient in metal reduction and in current production in MFCs [25], suggesting that pili may be involved in these processes. In this paper, we describe the generation of mutants that cannot produce Msh pili, type IV pili, or both due to deletion of the biogenesis genes needed for their production. Our results indicate that pili are not essential for extracellular electron transfer to metals or anode surfaces. Contrary to expectations, the $S$. oneidensis MR-1 type IV pili mutants generated more current in MFCs than the wild type. Extracellular levels of riboflavin, which acts as a soluble mediator in electron transfer, were similar in all strains, suggesting that reduction of this mediator cannot account for the observed differences in current output. Our data indicate that differences observed between wild type and mutant strains in current generation may be due to the effect of the mutations on cell attachment and direct electron transfer. Based on these results, we conclude that under the conditions studied, type IV pili do not play a role in extracellular electron transfer and that a majority of extracellular electron transfer to insoluble electron acceptors occurs through direct contact with the surface exposed outer membrane cytochromes.

\section{Experimental}

\subsection{Mutagenesis, Complementation and Protein Analysis of $S$. oneidensis MR-1}

A list of bacterial strains and plasmids used in this study is given in Table 1. Growth and reduction assays were as described previously [26]. BG167, a pilD mutant of $S$. oneidensis MR-1, was generated using the Mini-himar RB-1 transposon [27]. Chromosomal deletions of $g_{s p} G$, type IV pilus biogenesis, Msh pilus biogenesis, and flagellin genes were generated using the modified suicide plasmid $\mathrm{pER} 2$, a derivative of pDS3 [28] using described protocols [29]. DNA fragments for generation of deletions or complementation of mutants were amplified by PCR using Phusion polymerase (Clontech) and primers listed in Table 2. The broad host-range plasmid pJB3Cm6 [30] was used for the complementation experiments. Recombinant plasmids were transferred from E. coli $\beta 2155$ [31] to S. oneidensis strains by conjugation.

Western blot analyses were performed essentially as described previously [9]. Cells pellets were resuspended in SDS loading buffer [32], and proteins were resolved on 4$20 \%$ polyacrylamide gels (Pierce). Affinity-purified polyclonal GspG antisera were commercially generated against the GspG peptides (GCGNKDKADQQKAVSDIVAD and GCEEGYVKRLPQDPW) by Biosynthesis, Inc. (Lewisville, TX). Reactive bands were visualized using the SuperSignal West Pico chemiluminescent substrate (Pierce).

Table 1. List of strains and plasmids used in this study.

\begin{tabular}{|c|c|c|}
\hline Strain & Description & Source \\
\hline \multicolumn{3}{|l|}{ S. oneidensis } \\
\hline MR-1 & Lake Oneida isolate & [50] \\
\hline BG167 & pilD ::himar mutant, $\mathrm{Km}^{\mathrm{r}}$ & This work \\
\hline BG184 & BG167 complemented with pilD, $\mathrm{Km}^{\mathrm{r}}, \mathrm{Cm}^{\mathrm{r}}$ & This work \\
\hline SR675 & MR-1 $\Delta g s p G$ & This work \\
\hline SR682 & SR675 complemented with $g s p$ carried on pJBC1 & This work \\
\hline SR753 & MR-1 $\triangle$ pilMNOPQ; type IV pili biogenesis mutant & This work \\
\hline SR803 & MR-1 $\triangle m s h H I J K L M N E G B A C D O P Q ;$ Msh pili biogenesis mutant & This work \\
\hline SR804 & MR-1 mutant that lacks type IV and Msh pili biogenesis genes ( $\Delta$ pilM-Q $\Delta m s h H-Q)$ & This work \\
\hline SR860 & MR-1 $\triangle o m c A \Delta m t r C$ & [5] \\
\hline \multicolumn{3}{|l|}{ E. coli } \\
\hline EC100 & $m c r A, \Delta(m r r-h s d R M S-m c r B C), r e c A 1$ & Epicenter Technologies \\
\hline $\mathrm{EC}_{100 \mathrm{D}^{+}}$ & E. coli $\mathrm{EC} 100$ derivative, pir + & Epicenter \\
\hline$\beta 2155$ & $\Delta$ dap $A::$ erm lacZ $\Delta M 15\left(\mathrm{~F}^{\prime}\right.$ lac $Z \Delta M 15$ lacl $^{q}$, traD36, proA $A$, proB +$)$ pir $:: \mathrm{RP} 4, \mathrm{Km}^{\mathrm{r}}$ & {$[31]$} \\
\hline Plasmids & Description & Source \\
\hline pJB3Cm6 & Cloning and sequencing vector, $\mathrm{Cm}^{\mathrm{R}}$ & {$[30]$} \\
\hline $\mathrm{pJBC} 1$ & Cloning and sequencing plasmid, $\mathrm{Cm}^{\mathrm{R}}$ & This work \\
\hline pER2 & Derivative of $\mathrm{pDS} 3, \mathrm{GmR}$, sacB, ori $\mathrm{R} 6 \mathrm{~K}$ & This work \\
\hline pMini-himar & mini-himar transposon, oriT, $\mathrm{Km}^{\mathrm{R}}$ & {$[27]$} \\
\hline pRA1 & pilD in $\mathrm{pJB} 3 \mathrm{Cm} 6$ & This work \\
\hline pRA4 & $g s p G$ in $\mathrm{pJBC} 1$ & This work \\
\hline
\end{tabular}


Table 2. List of primers used in this study.

\begin{tabular}{lll}
\hline Primer & Sequence & Description \\
\hline pilDF & 5'-GCTGCGCCCTTATAGATTCTAGGTC & Complementation of pilD mutant \\
pilDR & 5'-GATTCTAGAAGGAGCGCAGCGACG & Deletion of pilMNOPQ \\
pilQF11 & 5'-GCATGAGCTCCACTTGAGCGGCAGCGC & \\
pilQR11 & 5'-GCATGGATCCGCCAGAGACCGCAACAGCCGC & \\
pilQF21 & 5'-GCATGGATCCGGCGGTTGCGATTGATA & \\
pilQR21 & 5'-GCATGCATGCATTACCCCACCTCCGAG & \\
mshOF1 & 5'-GAGCGTGAAGCTACGAGGCACACCTTCG & Deletion of $m s h$ operon \\
mshOR1 & 5'-GATCGGATCCGCTGTTTTCAGTTAGGTTTTCGT & \\
mshOF2 & 5'-GATCGGATCCCGAGTGAATTTCATCGATCCGC & \\
mshOR2 & 5'-CACAGTTGCGGCCATTGCTGGCAC & Deletion of gspG \\
gspGF & 5'-CAGCAGTGTGAGAAAGACCG & \\
gspGR & 5'-CTACATCTCCTAAAAAACCAGC & \\
gspHF & 5'-GGTTTTTTAGGAGATGTAGGATGTTAATGCTGCGCCA & Complementation of gspG mutant \\
gspHR & 5'-GTCAGTACCGTGCTTAATACCG & \\
gspGN & 5'-CGTACATATGCAAATGAACAAAAAGCAC & \\
gspGR1 & 5'-GTATAAGCTTGGCGCAGCATTAACATCT &
\end{tabular}

\subsection{Transmission and Scanning Electron Microscopy}

Mutant and wild-type cells were grown aerobically on minimal medium agar supplemented with $10 \mathrm{mM}$ lactate, or anaerobically on minimal medium supplemented with $50 \mathrm{mM}$ lactate and $10 \mathrm{mM}$ ferric citrate for 2 days at room temperature. Cells were gently scraped off the agar surface and resuspended in basal medium, and fixed with $1 \%$ paraformaldehyde. Formvar coated 200 carbon mesh grids were floated on the cell suspensions for $2 \mathrm{~min}$, washed with $\mathrm{dH}_{2} \mathrm{O}$ for $3 \mathrm{~min}$, and then stained with $2 \%$ uranyl acetate for $2 \mathrm{~min}$. Cells were viewed using a Hitachi (H600) transmission electron microscope (TEM) operating at $75 \mathrm{kV}$.

$S$. oneidensis wild type and mutant strains were grown similarly for scanning electron microscopy imaging. Cells were lifted off agar plates onto glass cover slips then fixed and treated as described previously [33]. Cover slips were coated with $2 \mathrm{~nm}$ iridium in an Emitech K575X sputter coater (Emitech, Ashford, England), and cells were viewed with a Hitachi S-4800 Field emission-scanning electron microscope (SEM; Hitachi, Pleasanton, CA) operating at $3 \mathrm{kV}$ and $4 \mathrm{~mm}$ working distance.

\subsection{Bacterial Culture for Microbial Fuel Cell Testing}

Overnight aerobically grown cultures of S. oneidensis MR-1 wild type and mutants were used to inoculate $25 \mathrm{~mL}$ of minimal medium [25] supplemented with $18 \mathrm{mM}$ sodium lactate. Cultures were grown in $50 \mathrm{~mL}$ conical tubes at $30^{\circ} \mathrm{C}$ in a shaker incubator $(140 \mathrm{rpm})$ for $48 \mathrm{~h}$. Cell numbers of all cultures were equalized to $1 \times 10^{8}$ cells $/ \mathrm{mL}$ using fresh minimal media. Cells prepared in this manner were tested three times for current production with each run performed in triplicate $(400 \mu \mathrm{L} / \mathrm{well})$ in an 18 well voltage based screening assay (VBSA).

\subsection{Microbial Fuel Cell Data Acquisition and Microscopic Analysis of Electrodes}

Dimensions and fabrication of the voltage based screening assay (VBSA) were published previously [34]. The anodes were single-sided carbon-coated titanium flags and the cathode system was graphite paper in $50 \mathrm{mM}$ potassium ferricyanide dissolved in $100 \mathrm{mM}$ phosphate buffer at $\mathrm{pH}$ 7.0. Experiments were performed at $25^{\circ} \mathrm{C}$ exposed to air. The conditions for the anodes during MFC operation are referred to as air-exposed but are most likely at reduced dissolved oxygen concentrations (DOC), since DOC in unshaken MR-1 cultures drops quickly to immeasurable levels $(<0.5 \mathrm{ppm})$. Triplicate experiments were performed in three separate 18-well VBSA devices. $20 \mathrm{mM}$ Sodium lactate was added to each anode chamber at $24 \mathrm{~h}$ and then every 36 hours. The voltages across a $100 \mathrm{k} \Omega$ resistor bank (in a custom 36-resistor bank made for simultaneous measurements) were recorded with a personal data acquisition device (I/O tech, personal daq/54) every four minutes. Ohm's law was used to convert voltage to current. Anodes were removed for environmental scanning electron microscopy (ESEM) analysis after 35, 100, and 210 hours of MFC operation. Unattached biomass was removed by washing anodes three times with $1 \mathrm{~mL}$ of phosphate buffered saline. Anodes were fixed with $4 \%$ cacodylate buffered glutaraldehyde [35] for at least 24 hours at 4 C. Anodes were then washed with $50 \mathrm{~mL}$ of distilled water for two minutes, then placed on a mounting stub on the Peltier cooling device inside the ESEM chamber and treated as described previously [34].

\subsection{High Performance Liquid Chromatography (HPLC)}

Supernatants from the wells of the air-exposed VBSA that had been in operation for $220 \mathrm{~h}$ were harvested and planktonic cells were removed via centrifugation and 
$0.1 \mu \mathrm{m}$ filtration. The resulting cell-free supernatants were tested for the presence of riboflavin and FMN via HPLC. Analyses were performed using a Shimadzu HPLC system with dual-plunger parallel flow solvent delivery modules (LC-20AD) and an autosampler (SIL-20AC) coupled to a fluorescence detector (RF-10AXL). The stationary phase was a $250 \mathrm{~mm}$ Altech Alltima C18 $(5 \mu \mathrm{m})$ analytical column with an isocratic 50:50 methanol:water mobile phase. Injection volumes of 5,10 , and $15 \mu \mathrm{l}$ were analyzed under a flow rate of $0.7 \mathrm{~mL} / \mathrm{min}$ with excitation at $450 \mathrm{~nm}$ and emission monitored at $530 \mathrm{~nm}$. This adapted method provided separation between the elution peaks of the fluorescent media components and those of riboflavin and FMN [36, 37]. Standard curves across the dynamic range of the method $(1 \mathrm{nM}$ to $10 \mu \mathrm{M})$ were used to quantify the riboflavin content of the samples. Controls included minimal medium only and minimal medium spiked with riboflavin or FMN.

\section{Results and Discussion}

\subsection{Processing of Type IV, Msh, and GspG Prepilins by PilD in S. oneidensis MR-1}

The $S$. oneidensis PilD is predicted to process type IV prepilins. In some bacteria, such as Pseudomonas aeruginosa and Vibrio cholerae, PilD plays a dual role and processes type IV and T2SS prepilins [38-41]. The genome sequence of $S$. oneidensis contains one type IV prepilin peptidase gene (pilD;SO_0414). A second prepilin peptidase gene that may be involved in processing of type II secretion system prepilins is absent. This suggested that PilD might play a dual role in processing type IV prepilins as well as T2S prepseudopilins. To test this prediction, we analyzed the pilD mutant for pili production and for processing of the major type II secretion pilin GspG. Transmission electron microscopy of negatively stained wild-type MR-1 cells revealed the presence of pili that were absent in the pilD mutant (Fig. 1A). Complementation of the mutant restored its ability to produce pili similar to the wild type.

The involvement of PilD in processing T2S prepilins was tested by Western blot analysis using antibodies raised towards GspG, the predicted major pilin of the T2S system in MR-1. Our results indicated that this protein was not processed in the pilD mutant (Fig. 1B). A reactive band of ca. $17 \mathrm{kDa}$ that corresponded to the prepilin protein (predicted size $16.16 \mathrm{kDa}$ ) was detected in the pilD mutant cell extract. A band of a lower molecular weight (15 kDa), which corresponded to the size of the processed pseudopilin, was observed in wild type and complemented mutant cell extracts. An additional band was detected in all samples, including the $\Delta g s p G$ cell extract. The nature of this crossreactive band is not known.

The results presented above indicate that in $S$. oneidensis MR-1, PilD processes type IV, Msh, and T2S prepilins. This
MR-1

A)

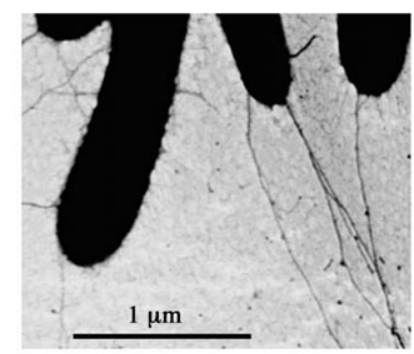

pilD::himar

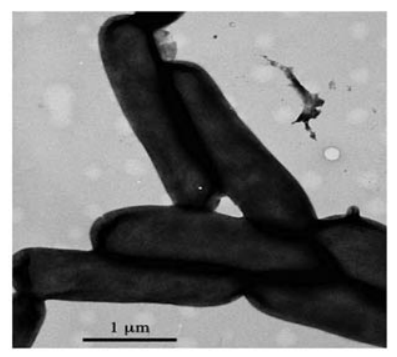

Complemented pilD

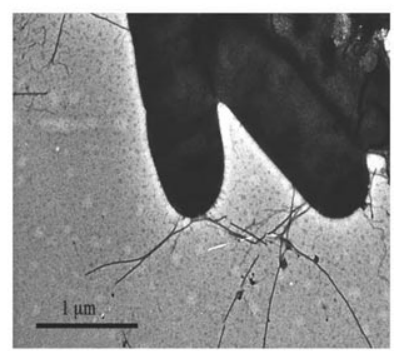

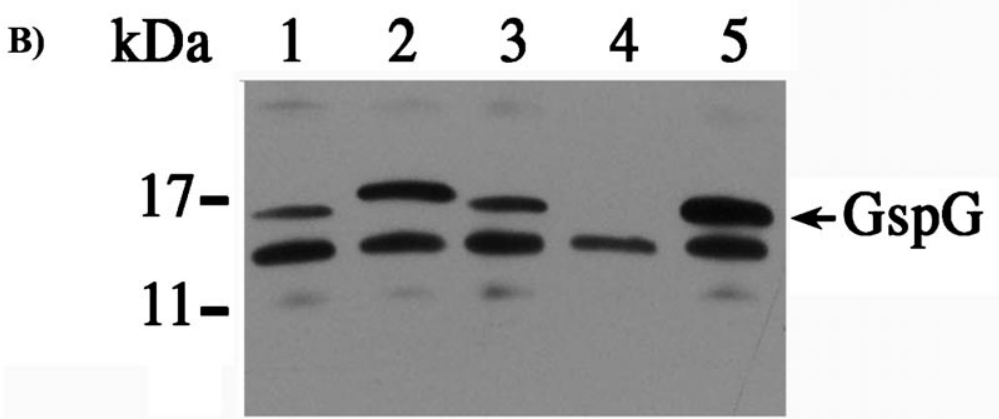

Fig. 1. (A) Electron micrographs of negatively stained wild type MR-1, pilD mutant, and complemented mutant cells. (B) Western blot analysis of cell extracts using GspG antibodies. Lane 1, wild type MR-1; lane 2, pilD deletion mutant; lane 3, complemented pilD mutant; lane 4, $\Delta \mathrm{gspG}$ mutant; lane 5, complemented $\Delta g s p G$ mutant. Equal amounts of total protein were loaded in each lane. 
result has important implications to previously published studies which determined that the PilD mutant had limited metal reduction and current generating capacity [25]. Our results indicate that this reduced ability to perform extracellular electron transfer could be due to either loss of pili or loss of surface cytochromes.

\subsection{Structural Analysis of S. oneidensis pil, msh, and flg Mutants}

Our results show that in addition to loss of pili, a PilD deficiency also leads to a nonfunctional T2SS. This secretion system in $S$. oneidensis was shown to be required for the proper localization of the outer membrane cytochromes, MtrC and OmcA, which are involved in electron transfer to anodes and to metal oxides $[18,25]$. In contrast, the nature and contribution of pilus-like structures to metal reduction and direct electron transfer in MFCs are not fully understood.

Analysis of the genome sequence of $S$. oneidensis indicated that this organism is capable of producing type IV and mannose sensitive hemagglutinin (Msh) pili. Two gene clusters, pilMNOPQ (SO_0281-SO_0285) and mshHIJKLMNEGBACDOPQ (SO_4100-SO_4116), are annotated as type IV and Msh pilus biogenesis systems, respectively. Since these are the only genes predicted to be involved in pili production, their deletion is expected to result in complete loss of pili. This was confirmed by negative staining and TEM or by scanning electron microscopy using cells grown aerobically and anaerobically (Fig. 2 and data not shown). Pili of approximately $5 \mathrm{~nm}$ in diameter were observed on the surface of wild type cells. The diameter of these appendages was similar to that of individual conductive nanofilaments reported earlier [20]. Similar structures were also observed on the surfaces of the mutants that lack either the type IV or Msh biogenesis systems (Fig. 2). Pili observed on the surface of $\triangle$ pilM- $Q$ likely corresponded to Msh pili, while pili observed on the surface of the $\Delta m s h H-Q$ mutant likely represent type IV pili. As expected, cells that lacked both type IV and Msh biogenesis systems failed to produce pili when grown aerobically or anaerobically (Fig. 2 and data not shown).

In addition to pili, $S$. oneidensis cells had polar flagella that were $15-18 \mathrm{~nm}$ in diameter. As a control, we generated a mutant $(\Delta f l g)$ that lacked the flagellin genes SO_3237 and SO_3238. This mutant lacked flagella but produced pili similar to the wild type (Fig. 2).

\subsection{Fe(III) Reduction and Current Generation by Pili and Flagella Deletion Mutants of $S$. oneidensis MR-1}

The role of pili and flagella in extracellular electron transfer to $\mathrm{Fe}(\mathrm{III})$ was tested using ferrihydrite, a poorly crystalline $\mathrm{Fe}(\mathrm{III})$ oxide. All nanofilament deletion mutants reduced ferrihydrite similar to the wild type (Fig. 3), while mutants that lack either a functional T2SS $(\Delta g s p G)$ or the two outer


Fig. 2. Transmission electron micrographs of wild-type MR-1 (A), $\Delta g s p G$ (B), $\Delta p i l M-Q$ (C), $\Delta m s h H-Q$ (D), $\Delta f l g$ (E), and $\Delta$ pilM-Q $\Delta m s h H-Q(\mathrm{~F})$ cells. Size bars, Pili (P) and flagella (F) are indicated.

membrane $c$ cytochormes needed for metal reduction $(\triangle m t r C / \triangle o m c A)$ were deficient in this process (Fig. 3). These results indicated that neither pili nor flagella were essential for extracellular electron transfer to $\mathrm{Fe}(\mathrm{III})$ by $S$. oneidensis MR-1.

We compared current production by the wild type, $\Delta$ pilM-Q, $\Delta m s h H-Q, \Delta p i l M-Q / \Delta m s h H-Q, \Delta f l g$, and $\Delta m t r C /$ $\triangle o m c A$ in a VBSA to determine the role of pili or flagella in direct electron transfer to anodes. The miniature modular design of the VBSA allowed the analysis of current generation trends between each mutant and the wild type as well as time-dependent images of biofilm formation on the anodes [34]. As expected, current production by $\Delta m t r C /$ $\triangle o m c A$ was negligible, comprising $15 \%$ of the current generated by wild-type MR-1 (Fig. 4) and is consistent with 




Fig. 3. Hydrous ferric oxide (HFO) reduction by wild type $(\diamond)$, $\Delta$ mshH-Q mutant (०), $\Delta$ pilM- $Q$ mutant $(\bullet)$, and $\Delta$ flg mutant $(\square)$, $\triangle$ gsp $G$ mutant $(*)$, and $\triangle m$ trClomc $A$ mutant $(\triangle)$.

earlier reports [25]. In contrast, pili and flagella mutants were able to generate current, indicating that these appendages are not required for electron transfer to the anode surface (Fig. 4). This is in agreement with the Fe(III) reduction results described above, indicating that the same mechanism is used by $S$. oneidensis MR-1 to transfer electrons outside the membrane to metal oxides and anode surfaces. Although all mutant strains generated current in MFCs, the flagella and type IV pili mutants $(\Delta \mathrm{flg}$ and $\triangle$ pilM-Q) produced twice as much current as the wild type $(0.8 \mu \mathrm{A}$ compared to $0.4 \mu \mathrm{A}$, Fig. 4$)$. In contrast, mutants that lack $m s h H-Q(\Delta m s h H-Q$ and $\Delta m s h H-Q / \Delta p i l M-Q)$ initially generated a similar amount of current as the wild type (Fig. 4), but by $150 \mathrm{~h}$ these levels started to decline and reached $50 \%$ of wild-type levels by the end of the experiment.

The differences in current production between wild type, pili and flagella mutants were not expected based on the observed metal reduction results (Fig. 3). Since MtrC and OmcA are the major reductases involved in extracellular electron transfer to metal oxides and anodes of MFCs, we expected the rate of electron transfer to these electron acceptors to be similar. The reason for the observed differences in electron transfer to ferrihydrite and anode surfaces is not clear. Formation of biominerals, such as magnetite $\left(\mathrm{Fe}_{3} \mathrm{O}_{4}\right)$, during ferrihydrite reduction, affects the rate of electron transfer reactions [42], and may partially explain the differences in electron transfer rates to ferrihydrite compared to anode surfaces.

One factor that plays an important role in direct extracellular electron transfer is biofilm formation. The presence of well-developed biofilms has been associated with increased current output in MFCs [34]. Biofilm formation, which impacts current production by $S$. oneidensis [43, 44], involves type IV pili, Msh pili, and flagella [45]. In our experiments, we correlated current output with biofilm formation over time (arrows on Figure 4 indicate the times at which anodes were removed from the VBSA and observed by ESEM). Observation of cell attachment to the anodes by ESEM imaging indicates that current output is not directly proportional to biofilm formation by anodeattached cells of the flagella mutant. Flagella mutant cells did not appear to colonize the anode surfaces efficiently (Fig. 5), but was able to generate more current than the wild type. One factor that may contribute to these differences is settling of cells on the anode surface. Since flagella mutants are not able to swim, a higher number of these cells may settle on the anode surface compared to the wild type. Cells that settle on the anode surface, but do not attach, will not be imaged due to washing of anodes prior to performing ESEM. It is therefore possible that the observed increase in current output for the flagella mutant was due to settled cells on the anode surface.

In contrast to the flagella mutant, current production and biofilm formation appeared to be directly proportional in cells that lacked Msh pili. These mutants initially produced current similar to the wild type, but then declined to $50 \%$ by the end of the experiment (Fig. 4). Attachment of the mshH$Q$ deletion mutants to anode surfaces appeared to be severely compromised (Fig. 5). This is in agreement with the finding that Msh pili are needed for attachment and initial stages of biofilm formation [45]. This severe deficiency in attachment may partly explain the decreased current output by the $\Delta m s h H-Q$ mutant. Cell attachment to the anode over time for the wild type contributes to the rise in current throughout the experiment, while the inability for $\Delta m s h H$ $Q$ mutant cells to attach to the electrode appears to limit its ability to generate current.

The most surprising result of our experiments was the disproportionate increase in current output compared to cell attachment by the type IV pili mutant $(\Delta p i l M-Q)$. This mutant produced almost twice as much current as the wild type (Fig. 4), yet both strains colonized the anode surfaces in a similar manner (Fig. 5). Clearly, differences in current output between this mutant and the wild type cannot be simply explained as a result of differences in attachment and biofilm formation, or by cell settling due to lack of motility. Type IV pili in S. oneidensis were shown to be involved in the later stages of biofilm formation, but not in initial attachment [45]. Additional work is needed to fully understand the effect of pili and their role in the different stages of biofilm formation on current production in MFCs. However, from our results we can conclude that under the conditions of our experiments, flagella and type IV pili are not essential for extracellular electron transfer and current generation by $S$. oneidensis MR-1, while Msh pili may be indirectly involved in electron transfer, most likely due to their role in cell attachment.

\subsection{Role of Riboflavins in Extracellular Electron Transfer in pil, msh and flg Mutants}

One of the most intriguing results of this study was the finding that $\Delta$ flg and $\Delta p i l M-Q$ cells were more efficient in electron transfer to anode surfaces than the wild type. Recently, flavins were proposed to be soluble mediators in 




Fig. 4. Wild type and mutant Shewanella strains tested using voltage-based screening assay (VBSA). Average electrical current output from $S$. oneidensis MR-1 (WT), $\Delta f l g, \Delta p i l M-Q, \Delta m s h H-Q, \Delta p i l M-Q / \Delta m s h H-Q, m t r C / \Delta o m c A$ from an air-exposed 18-well VBSA with lactate as the sole electron source.

extracellular electron transfer to $\mathrm{Fe}(\mathrm{III})$ oxides and to anodes of MFCs [22, 23]. To determine if these mediators contributed to the differences in current output by wild type and mutant strains, we measured flavin levels in culture supernatants at the end of the MFC experiments $(210 \mathrm{~h})$. Riboflavin appeared to be the dominant species in the supernatants of all cultures tested (Fig. 6). Although flavin adenine mononcleotide (FMN) has been detected in supernatants of different Shewanella species [23], we did not detect it in our experiments, perhaps due to differences in experimental design. Surprisingly, the levels of riboflavins in supernatants of $\Delta f l g, \Delta m s h, \Delta p i l M-Q, \Delta m t r C / \Delta o m c A$ were similar to wild type levels (Fig. 6). If reduction of riboflavins was the predominant mechanism used for electron transfer [22], all strains would be expected to produce similar amounts of current, due to limiting concentrations of the riboflavin mediator. The presence of riboflavin in all culture supernatants would suggest that the ability to perform indirect (mediated) electron transfer exists at equal probabilities for all mutants. The deficiency of $\Delta m t r C / \Delta o m c A$ mutant in metal reduction and current generation, in the presence of normal levels of extracellular riboflavin, indicates that outer surface cytochromes are necessary for extracellular electron transfer to occur. Additionally, due to the similar level of riboflavin found for the wild type, $\Delta f l g$ and $\Delta$ pilM-Q, we can conclude that the enhanced current generated by the deletion mutants was not due to the excess biosynthesis of mediator.

\section{Conclusions}

Several mechanisms have been proposed to explain extracellular electron transfer to insoluble metal oxides and anode surfaces by metal reducing bacteria. These include direct reduction through contact with the metal oxide, and indirect mechanisms where reduction occurs at a distance through the use of soluble shuttle compounds [21-23, 4649]. Direct contact is proposed to occur through contact of the outer membrane $c$ cytochromes, MtrC and OmcA, with the electron acceptor, or through pilus-like structures, or nanowires. The structure and nature of pilus-like structures are not known. In an attempt to identify these structures, we generated mutants that are not capable of pili formation under any growth condition due to loss of the biogenesis systems required for their production. Our results indicated that none of the known surface appendages of $S$. oneidensis appear to be required for direct electron transfer to metal oxides or anode surfaces, although they appear to influence current output levels in MFCs. Deletion of type IV pili increased current output, while loss of Msh type pili resulted in decreased output over time.

In S. oneidensis MR-1, extracellular electron transfer by direct contact and indirect reduction through soluble mediators appear to be intimately linked. The link consists of the two outer membrane cytochromes, Mtrc and OmcA. In the absence of surface exposure of these proteins on $S$. oneidensis cells, reduction of riboflavins, $\mathrm{Fe}(\mathrm{III})$, or anodes in MFCs is barely detectable. The promiscuity of these outer membrane cytochromes provides MR-1 with an advantage in its natural environment, where it can, in the absence of 

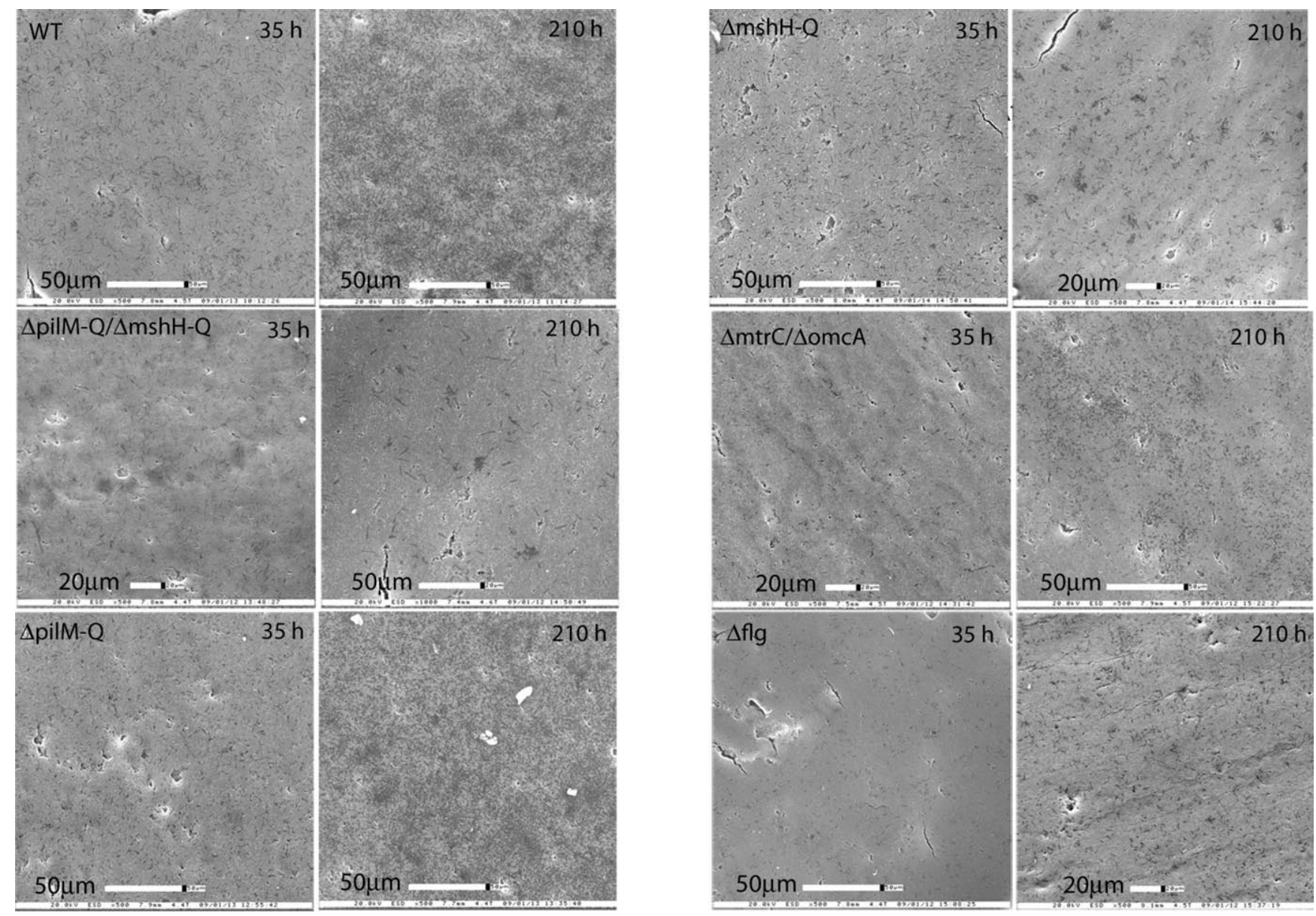

Fig. 5. Environmental SEM of biofilms on MFC anodes with time. Anodes from wild type and mutant strains were harvested from the VBSA at the times indicated by arrows in Fig. 4 (100 h data not shown).

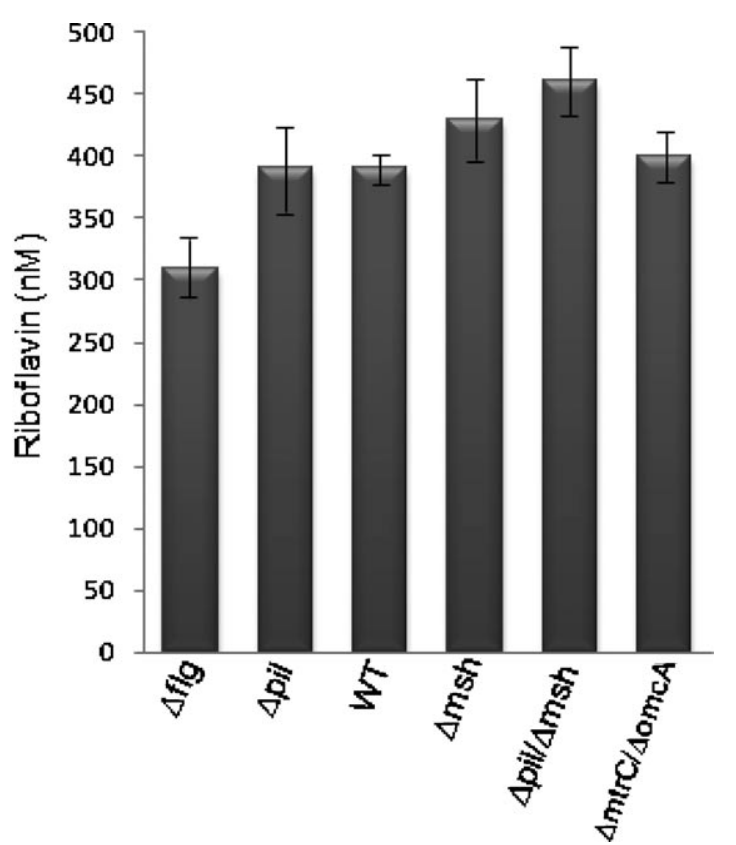

Fig. 6. Presence of riboflavin in cell-free supernatants from the wells of a VBSA after $220 \mathrm{~h}$ of operation as determined by HPLC. Data shown represent means $\pm S D$ of triplicate determinations. internal electron acceptors, transfer electrons extracellulary to soluble or solid acceptors.

\section{Acknowledgements}

We thank Mark McBride for helpful comments and critical reading of the manuscript. This research was supported by the U.S. Department of Energy (DOE) Office of Biological and Environmental Research under the Genomics:GTL Program via the Shewanella Federation consortium, the Environmental Remediation Sciences Program (ERSP), by EMSL Scientific Grand Challenge Project at the W.R. Wiley Environmental Molecular Sciences Laboratory, a national scientific user facility sponsored by OBER and located at Pacific Northwest National Laboratory (PNNL), Office of Naval Research through NRL PE\#61153N, and by NSF instrument acquisition Grant CHE\#0723002. Battelle Memorial Institute operates Northwest National Laboratory for the DOE under contract DE-AC05-76RL01830. We thank the National Research Council for L.A.F. Postdoctoral Fellowship. 


\section{References}

[1] J. Myers, C. Myers, J. Appl. Microbiol. 2000, 88, 98.

[2] K. Nealson, D. Saffarini, Ann. Rev. Microbiol. 1994, 48, 311.

[3] R. Bencheikh-Latmani, S. M. Williams, L. Haucke, C. S. Criddle, L. Wu, J. Zhou, B. M. Tebo, Appl. Environ. Microbiol. 2005, 71, 7453 .

[4] C. Liu, Y. A. Gorby, J. M. Zachara, J. K. Fredrickson, C. F. Brown, Biotechnol. Bioeng. 2002, 80, 637.

[5] M. J. Marshall, A. S. Beliaev, A. C. Dohnalkova, D. W. Kennedy, L. Shi, Z. Wang, M. I. Boyanov, B. Lai, K. M. Kemner, J. S. McLean, S. B. Reed, D. E. Culley, V. L. Bailey, C. J. Simonson, D. A. Saffarini, M. F. Romine, J. M. Zachara, J. K. Fredrickson, PLoS Biol. 2006, 4, e268.

[6] M. J. Marshall, A. E. Plymale, D. W. Kennedy, L. Shi, Z. Wang, S. B. Reed, A. C. Dohnalkova, C. J. Simonson, C. Liu, D. A. Saffarini, M. F. Romine, J. M. Zachara, A. S. Beliaev, J. K. Fredrickson, Environ. Microbiol. 2007.

[7] J. M. Myers, W. E. Antholine, C. R. Myers, Appl. Environ. Microbiol. 2004, 70, 1405.

[8] A. Beliaev, D. Saffarini, J. Bacteriol. 1998, 180, 6292.

[9] A. Beliaev, D. Saffarini, J. McLaughlin, D. Hunnicut, Mol. Microbiol. 2001, 39, 722.

[10] C. R. Myers, J. M. Myers, Lett. Appl. Microbiol. 2003, 37, 254.

[11] J. M. Myers, C. R. Myers, Biochim. Biophys. Acta 1998, 1373, 237.

[12] D. E. Ross, S. S. Ruebush, S. L. Brantley, R. S. Hartshorne, T. A. Clarke, D. J. Richardson, M. Tien, Appl. Environ. Microbiol. 2007, 73, 5797.

[13] N. S. Wigginton, K. M. Rosso, M. F. Hochella, J. Phys. Chem. B 2007, 111, 12857.

[14] T. DiChristina, C. Moore, C. Haller, J. Bacteriol. 2002, 184, 142.

[15] B. C. Kim, C. Leang, Y. H. Ding, R. H. Glaven, M. V. Coppi, D. R. Lovley, J. Bacteriol. 2005, 187, 4505.

[16] B. C. Kim, X. Qian, C. Leang, M. V. Coppi, D. R. Lovley, J. Bacteriol. 2006, 188, 3138.

[17] T. Mehta, M. V. Coppi, S. E. Childers, D. R. Lovley, Appl. Environ. Microbiol. 2005, 71, 8634.

[18] L. Shi, S. Deng, M. J. Marshall, Z. Wang, D. W. Kennedy, A. C. Dohnalkova, H. M. Mottaz, E. A. Hill, Y. A. Gorby, A. S. Beliaev, D. J. Richardson, J. M. Zachara, J. K. Fredrickson, J. Bacteriol. 2008, 190, 5512.

[19] T. Mehta, S. Childers, R. Glaven, D. Lovley, T. Mester, Microbiology 2006, 152, 2257.

[20] Y. A. Gorby, S. Yanina, J. S. McLean, K. M. Rosso, D. Moyles, A. Dohnalkova, T. J. Beveridge, I. S. Chang, B. H. Kim, K. S. Kim, D. E. Culley, S. B. Reed, M. F. Romine, D. A. Saffarini, E. A. Hill, L. Shi, D. A. Elias, D. W. Kennedy, G. Pinchuk, K. Watanabe, S. Ishii, B. Logan, K. H. Nealson, J. K. Fredrickson, Proc. Natl. Acad. Sci. USA 2006, 103, 11358.

[21] G. Reguera, K. D. McCarthy, T. Mehta, J. S. Nicoll, M. T. Tuominen, D. R. Lovley, Nature 2005, 435, 1098.

[22] E. Marsili, D. Baron, I. Shikhare, D. Coursolle, J. Gralnick, D. Bond, Proc. Natl. Acad. Sci. USA 2008, 105, 3968.

[23] H. von Canstein, J. Ogawa, S. Shimizu, J. R. Lloyd, Appl. Environ. Microbiol. 2008, 74, 615.
[24] J. C. Biffinger, J. Pietron, O. Bretschger, L. Nadeau, G. Johnson, C. Williams, K. Nealson, B. R. Ringeisen, Biosens. Bioelectron. 2008, 24, 906.

[25] O. Bretschger, A. Obraztsova, C. A. Sturm, I. S. Chang, Y. A Gorby, S. B. Reed, D. E. Culley, C. L. Reardon, S. Barua M. F. Romine, J. Zhou, A. S. Beliaev, R. Bouhenni, D. Saffarini, F. Mansfeld, B. H. Kim, J. K. Fredrickson, K. H. Nealson, Appl. Environ. Microbiol. 2007, 73, 7003.

[26] D. A. Saffarini, R. Schultz, A. Beliaev, J. Bacteriol. 2003, 185, 3668.

[27] R. Bouhenni, A. Gehrke, D. Saffarini, Appl. Environ. Microbiol. 2005, 71, 4935.

[28] X. Wan, N. VerBerkmoes, L. A. McCue, D. Stanek, H. Connelly, L. Hauser, L. Wu, X. Liu, T. Yan, A. Leaphart, R. Hettich, J. Zhou, D. Thompson, J. Bacteriol. 2004, 186, 8385.

[29] M. Charania, K. Brockman, Y. Zhang, A. Banerjee, G Pinchuk, J. Fredrickson, A. Beliaev, D. Saffarini, J. Bacteriol. 2009, 191, 4298.

[30] J. M. Blatny, T. Brautaset, H. C. Winther-Larsen, K. Haugan, S. Valla, Appl. Environ. Microbiol. 1997, 63, 370.

[31] C. Dehio, M. Meyer, J. Bacteriol. 1997, 179, 538.

[32] U. K. Laemmli, Nature 1970, 227, 680.

[33] N. Dekker, C. Lammel, G. Brooks, J. Electron. Microsc. Tech. 1991, 19, 461.

[34] J. C. Biffinger, R. Ray, B. J. Little, L. A. Fitzgerald, M. Ribbens, S. E. Finkel, B. R. Ringeisen, Biotechnol. Bioeng. 2009, 103, 524.

[35] R. Ray, B. J. Little, P. Wagner, K. Hart, Scanning 1997, 19, 98.

[36] S. Ashoor, G. Seperich, W. monte, J. Welty, J. Food Sci. 1983 $48,92$.

[37] M. Chen, D. Andrenyak, D. Moody, R. Foltz, J. Chromatogr. B 2005, 820, 147.

[38] B. Dupuy, M. K. Taha, O. Possot, C. Marchal, A. P. Pugsley, Mol. Microbiol. 1992, 6, 1887.

[39] J. W. Marsh, R. K. Taylor, Mol. Microbiol. 1998, 29, 1481.

[40] A. P. Pugsley, B. Dupuy, Mol. Microbiol. 1992, 6, 751.

[41] M. S. Strom, D. Nunn, S. Lory, Methods Enzymol. 1994, 235, 527.

[42] J. Zachara, R. Kukkadapu, J. Fredrickson, U. Gorby, S. C. Smith, Geomicrobiol. J. 2002, 19, 179.

[43] J. C. Biffinger, J. Pietron, R. Ray, B. Little, B. R. Ringeisen, Biosens. Bioelectron. 2007, 22, 1672.

[44] B. Kim, I. Chang, G. Gadd, Appl. Microbiol. Biotechnol. 2007, 76, 485 .

[45] K. Thormann, R. Saville, S. Shukla, D. Pelletier, A. Spormann, J. Bacteriol. 2004, 186, 8096.

[46] D. P. Lies, M. E. Hernandez, A. Kappler, R. E. Mielke, J. A. Gralnick, D. K. Newman, Appl. Environ. Microbiol. 2005, 71, 4414.

[47] G. Reguera, K. Nevin, J. S. Nicoll, S. Covalla, T. Woodward, D. Lovley, Appl. Environ. Microbiol. 2006, 72, 7345.

[48] B. Lower, L. Shi, R. Yongsunthon, T. Droubay, D. McCready, S. K. Lower, J. Bacteriol. 2007, 189, 4994.

[49] M. Taillefert, J. Beckler, E. Carey, J. Burns, C. Fennessey, T DiChristina, J. Inorg. Biochem. 2007, 101, 1760.

[50] C. Myers, K. Nealson, Science 1988, 240, 1319. 